and time-dependent. The determination of the temperature during continuum emission therefore cannot be made with any certainty. Even if it is assumed that ionization equilibrium exists at the peak of continuum emission, results are not in accord with the dependence of continuum intensity on the square of the equilibrium ion concentration predicted by Unsöld. ${ }^{2}$

\section{ACKNOWLEDGMENTS}

The authors gratefully acknowledge valuable discussions with $\mathrm{Y}$. Tanaka of the Air Force Cambridge Research Center and C. Kenty of the General Electric Company.

We are indebted to G. L. Brengelmann for photometry of the spectrum of the reflected shock in xenon.

\title{
Thermodynamics of Nonstoichiometric Nickel Tellurides. II. Dissociation Pressures and Phase Relations of Tellurium-Rich Compositions*
}

\author{
Edgar F. Westrum, JR., and R. E. Machor $\dagger$ \\ Department of Chemistry, University of Michigan, Ann Arbor, Michigan
}

(Received June 9, 1958)

\begin{abstract}
Dissociation pressures of tellurium over liquid and solid nickel telluride solutions have been measured with a silica Bourdon gauge at compositions corresponding to $\mathrm{NiTe}_{1.5}, \mathrm{NiTe}_{1.7}, \mathrm{NiTe}_{1.2}, \mathrm{NiTe}_{2.0}$, and $\mathrm{NiTe}_{2}$ at temperatures up to $780^{\circ}$. Modifications of the manometric technique are described which permit accuracies of $0.1 \mathrm{~mm}$ pressure and $0.1^{\circ}$ at high temperatures with corrosive substances where the pressure is sensitive to impurities or to composition changes. The results, together with data on the vapor pressure of pure tellurium, define the partial molal free energies and entropies of tellurium and, together with direct eutectic temperature measurement, delineate features of the phase diagram for compositions with more than 60 atomic percent tellurium.
\end{abstract}

\section{INTRODUCTION}

$\mathbf{T}$ HE interesting nature of the nickel/tellurium system, and an outline of the previous literature, have been presented in a previous paper, ${ }^{1}$ which also reported the heat capacity and thermodynamic functions up to room temperature. The present research was undertaken as part of a continuing program directed toward the determination of zero-point entropies as a function of composition of nickel tellurides.

The equilibrium pressure of tellurium vapor over various compositions of nickel tellurides from 60 to 100 atomic percent tellurium was measured at temperatures up to $780^{\circ}$. These measurements determined the phase behavior over this region with the exception of the eutectic, which is almost degenerate in that the composition differs only very slightly from pure tellurium. The eutectic temperature and composition were determined directly.

\section{EXPERIMENTAL}

\section{Vapor Pressure Measurement}

Of the methods available for the measurement of vapor pressure, few are capable of being applied with

\footnotetext{
* This work was submitted to the H. H. Rackham School of Graduate Studies in partial fulfillment of the requirements of the Ph.D. degree of R. E. Machol.

$\dagger$ Present address: Department of Electrical Engineering, Purdue University, Lafayette, Indiana.

I Westrum, Gronvold, Chou, and Machol, J. Chem. Phys. 28, 497 (1958).
}

accuracy at high temperatures. Effusion methods are accurate, but are limited to pressures lower than about $0.1 \mathrm{~mm}$. Dynamic methods in general are indirect and, therefore, subject to systematic errors; furthermore, they are difficult to apply to multicomponent substances where the pressure changes as the material is progressively vaporized. Static methods, on the other hand, are subject to errors from minute amounts of impurities, particularly those which are volatile and insoluble in the sample. In both cases there are other "difficulties and sources of error which increase exponentially with the temperature."' The present method is based on the use of a Bourdon gauge of vitreous silica used as a null instrument between the hot vapor to be measured and an inert gas, the pressure of the latter being measured on a conventional manometer. Such Bourdon gauges have been described in the literature ${ }^{3}$ for measuring vapor pressure. The principal refinements and modifications concern methods of outgassing the apparatus; purifying the sample; insuring uniformity and accuracy of measurement of sample temperature; observing the deflections of the gauge

${ }^{2} O$. Kubaschewski and E. L. Evans, Melallurgical Thermochemisiry (John Wiley and Sons, Inc., New York, 1956), second edition, p. 171 .

${ }^{3}$ J. R. Partington, An Advanced Treatise on Physical Chemistry (Longmans, Green, and Company, London), Vol. 1 (1949), p. $565 \mathrm{ff}$; Vol. 2 (1951), pp. 233 ff, 234 f. Kubaschewski and Evans, reference 2, pp. 145-147. Cf. Phipps, Spealman, and Cooke, J. Chem. Educ. 12, 321 (1935). 
accurately; and sealing the sample under vacuum in such a way that the apparatus can be opened again without breaking the fragile gauge.

A schematic cross section of the apparatus is shown in Fig. 1. The portion of the gauge within the furnace $(I, J, K, L, M)$ is vitreous silica. The sample $(U)$, whose pressure is to be measured, is placed in the sample space, and the entire apparatus placed in the furnace. Vapor from the sample exerts its pressure in the Bourdon gauge $(J)$, moving the pointer $(H)$ to the right. Inert gas is then admitted until the pointer $(H)$ is again aligned with the reference pointer, and the pressure of this inert gas measured on a mercury manometer.

The sickle-shaped silica Bourdon gauge $(J)$ was about $0.035 \mathrm{~mm}$ thick. It was tested before use at $10 \mathrm{~mm}$ positive and negative pressures; it ruptured at about $30 \mathrm{~mm}$ pressure. A pressure of $0.1 \mathrm{~mm}$ caused a deflection of the pointer $(H)$ of about $0.025 \mathrm{~mm}$. This deflection could be easily detected with a telescope through a small window in the furnace without mechanical or optical-lever magnification, because tungsten or rhodium wires $(0.15 \mathrm{~mm}$ diam $)$ were sealed at $(H)$ into thick silica pointers (about $2 \mathrm{~mm}$ diam) and heavily illuminated through a silica "light pipe" $(C)$. Vibration of the movable pointer was eliminated by eliminating thin spots in the pointer between $(J)$ and $(B)$, by rounding sharp edges of the gauge, and by supporting the apparatus rigidly in the furnace at both ends.

The sample tube was immersed in a silver block $(R)$ and the temperature of this block was measured with two $\mathrm{Pt}$ vs $\mathrm{Pt}-\mathrm{Rh}$ thermocouples $(T, V)$ which were repeatedly calibrated in situ by melting standard samples of zinc $\left(419.50^{\circ}\right)$, aluminum $\left(660.15^{\circ}\right)$, and copper-silver eutectic $\left(779.2^{\circ}\right)$ in graphite crucibles in the sample space. Temperature accuracy was $0.1^{\circ}$ and thermal homogeneity within the block (and sample) considerably better; radial uniformity was ensured by a uniform, symmetric, helical winding on the Alundum furnace tube $(N)$ and axial uniformity by insulators $(Q)$ between the silver and a surrounding aluminum bronze block $(P, S)$. Temperature constancy within $0.02^{\circ}$ per minute was achieved with a manually controlled autotransformer.

The weighed sample was introduced through the butt joint $(M)$ which was then sealed with a torch, and the apparatus immediately placed in the furnace and connected to a high-vacuum system. Outgassing was performed at $800^{\circ}$ and $10^{-6} \mathrm{~mm}$ for $30-100$ hoursuntil the pressure would not rise above $10^{-5} \mathrm{~mm}$ in five minutes with the pump disconnected and the entire apparatus at $800^{\circ}$. Less thorough outgassing leads to the development of appreciable pressure after the apparatus is sealed off; the offending gas has been spectroscopically identified as essentially pure carbon monoxide. During the outgassing, much of the tellurium distils up and lodges at $(E)$. After outgassing,

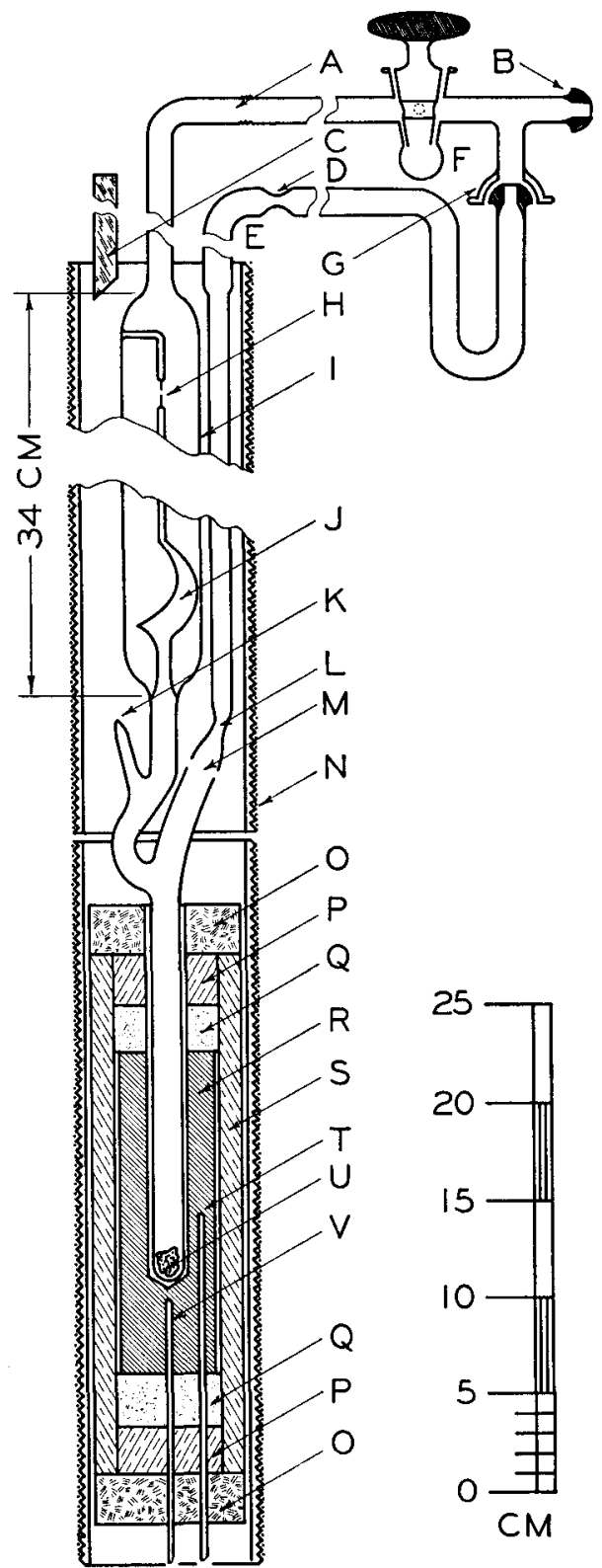

FIG. 1. Vapor pressure apparatus. Bourdon gauge $(J)$ with pointers $(H)$ and sample $(U)$ in silver cylinder $(R)$ within bronze cylinder $(S)$ with shrunk fit ends $(P) .(O, Q)$ are thermal insulation, $(A)$ is a silica to Pyrex graded seal; other symbols are explained in the text.

the constriction at $(D)$ is sealed off, and the apparatus removed from the furnace. The tellurium is distilled past the constriction $(L)$ at as low a temperature as possible, and this constriction is sealed off, after which the vapor pressure measurements may be made.

For subsequent experiments, the silica must be opened without subjecting the gauge to differential pressure. For this purpose, the crack-off tip $(K)$ is scratched and connected with a rubber and glass tubing to ball-joint $(G)$, connection is made through $(B)$ to a vacuum system, the apparatus pumped down, and stopcock $(F)$ opened. The crack-off tip is then broken 
Table I. Measured dissociation pressures of nickel tellurides.

\begin{tabular}{|c|c|c|c|c|c|}
\hline$t,{ }^{\circ} \mathrm{C}$ & $P(\mathrm{~mm})$ & $t,{ }^{\circ} \mathrm{C}$ & $P(\mathrm{~mm})$ & $t,{ }^{\circ} \mathrm{C}$ & $P(\mathrm{~mm})$ \\
\hline \multicolumn{2}{|c|}{$\mathrm{NiTe}_{2.00}$, Run 1} & \multicolumn{2}{|c|}{$\mathrm{NiTe}_{1.50}$} & 701.1 & 2.46 \\
\hline 781.9 & 45.28 & 666.6 & 8.11 & 765.2 & 12.46 \\
\hline 755.0 & 38.21 & 678.1 & 11.03 & 747.0 & 7.97 \\
\hline 728.6 & 30.25 & 687.7 & 14.21 & 732.0 & 5.46 \\
\hline 700.2 & 22.59 & 697.2 & 18.17 & 712.4 & 3.46 \\
\hline 667.9 & 15.23 & 653.0 & 5.42 & 695.8 & 2.25 \\
\hline 632.7 & 9.06 & 638.6 & 3.54 & 623.0 & 0.44 \\
\hline 597.4 & 4.93 & 623.1 & 2.29 & \multirow{2}{*}{\multicolumn{2}{|c|}{$\mathrm{NiTe}_{9}$}} \\
\hline 562.3 & 2.64 & 599.5 & 1.07 & & \\
\hline \multirow{2}{*}{\multicolumn{2}{|c|}{$\mathrm{NiTe}_{2,00}$, Run 2}} & 653.0 & 5.40 & 544.0 & 1.73 \\
\hline & & 697.2 & 18.13 & 620.1 & 7.29 \\
\hline 699.6 & 22.13 & 783.7 & 46.09 & 698.2 & 22.78 \\
\hline 689.6 & 19.62 & 773.8 & 43.64 & 686.0 & 19.00 \\
\hline 679.6 & 17.38 & 761.6 & 40.26 & 670.6 & 15.39 \\
\hline 667.2 & 14.84 & 749.6 & 36.87 & 655.1 & 12.44 \\
\hline 655.6 & 12.55 & 735.5 & 32.50 & 638.7 & 9.78 \\
\hline 643.5 & 10.55 & 721.9 & 28.43 & 620.1 & 7.34 \\
\hline 630.4 & 8.37 & 710.5 & 24.62 & 604.2 & 5.73 \\
\hline 615.9 & 6.80 & 697.2 & 17.97 & 587.4 & 4.23 \\
\hline 599.0 & 5.10 & 653.0 & 5.50 & 565.9 & 2.94 \\
\hline 564.5 & 2.74 & 599.5 & 1.22 & 544.0 & 1.85 \\
\hline 777.4 & 44.32 & \multirow{3}{*}{\multicolumn{2}{|c|}{$\mathrm{NiTe}_{1.50}$}} & 525.6 & 1.27 \\
\hline 766.0 & 41.38 & & & 511.3 & 0.92 \\
\hline 755.6 & 38.39 & & & 489.8 & 0.62 \\
\hline 744.5 & 35.12 & 688.0 & 0.7 & 548.8 & 1.94 \\
\hline 744.5 & 35.10 & 781.0 & 5.0 & 620.1 & 7.29 \\
\hline 731.9 & 31.21 & \multirow{3}{*}{\multicolumn{2}{|c|}{$\mathrm{NiTe}_{1.70}$}} & 698.2 & 23.11 \\
\hline 719.4 & 27.56 & & & 783.3 & 70.42 \\
\hline 707.1 & 24.17 & & & 771.4 & 61.53 \\
\hline 699.6 & 22.28 & 672.9 & 1.32 & 757.3 & 51.56 \\
\hline 627.0 & 8.16 & 652.1 & 0.73 & 743.3 & 43.12 \\
\hline 574.7 & 3.37 & 623.0 & 0.43 & 727.7 & 34.81 \\
\hline \multirow[t]{2}{*}{538.4} & 1.68 & 592.1 & 0.23 & 714.3 & 28.96 \\
\hline & & 623.0 & 0.39 & 698.2 & 22.92 \\
\hline
\end{tabular}

and inert gas slowly admitted. When atmospheric pressure is reached, a blowing tube is inserted at $(B)$, the silica opened at $(L)$ with an oxyhydrogen torch, and the butt joint $(M)$ again prepared. The appropriate weighed amount of tellurium is then added to bring the sample up to the next desired composition.

The principal source of error in the pressure measurements was due to shifts in the zero point. Null readings on the gauge were taken at the beginning and end of each day's measurements, usually with the gauge at $750^{\circ}$ and the sample at $420^{\circ}$. The pressure required to bring the pointer to the null position invariably increased during the day by 0.1 to $0.4 \mathrm{~mm}$. The cause of these shifts is unknown.

Errors due to thermal diffusion were eliminated by using large tubes. Errors resulting from change in composition were avoided by correcting for the vapor space (approximately $45 \mathrm{cc}$ ).

The samples of nickel tellurides were those previously described, ${ }^{1}$ or were made by mixing these samples in the appropriate proportions with each other or with tellurium (semiconductor grade, purity $99.999+\%$, procured from American Smelting and Refining Company). The results are presented in Table $\mathrm{I}$, in chronological order. The later data are probably slightly more reliable than the earlier data.
All pressure measurements are reported in terms of mercury at $0^{\circ} \mathrm{C}$ at standard gravity. It is believed unlikely that there are any systematic errors in the data of greater magnitude than $0.1 \mathrm{~mm}$, with the possible exception that some or all the samples may have been contaminated by $\mathrm{TeO}_{2}$, which might have had an effect as great as one-third $\mathrm{mm}$ at the highest temperatures reached.

All of the samples were outgassed at $800^{\circ} \mathrm{C}$ in high vacuum, resulting in distilling out much of the tellurium, which was subsequently distilled back. Thereafter several hours at $700^{\circ} \mathrm{C}$ were required before equilibrium pressures were obtained, indicating that this much time was required for the tellurium to diffuse into the center of each crystallite to effect homogeneity within about $0.1 \%$. On subsequent measurements, however, no lack of equilibrium could be detected, indicating that homogenization within a thin surface layer, and resulting equilibrium with the vapor phase, was achieved within the few minutes required to bring the furnace to equilibrium. For this reason the first few measurements on $\mathrm{NiTe}_{1.9}$ and $\mathrm{NiTe}_{1.7}$ were high and have been omitted from Table I. No other observations are omitted. The first points on $\mathrm{NiTe}_{2}$ and $\mathrm{NiTe}_{9}$ are retained because the vapor pressure of a liquid is not subject to such lack of equilibria.

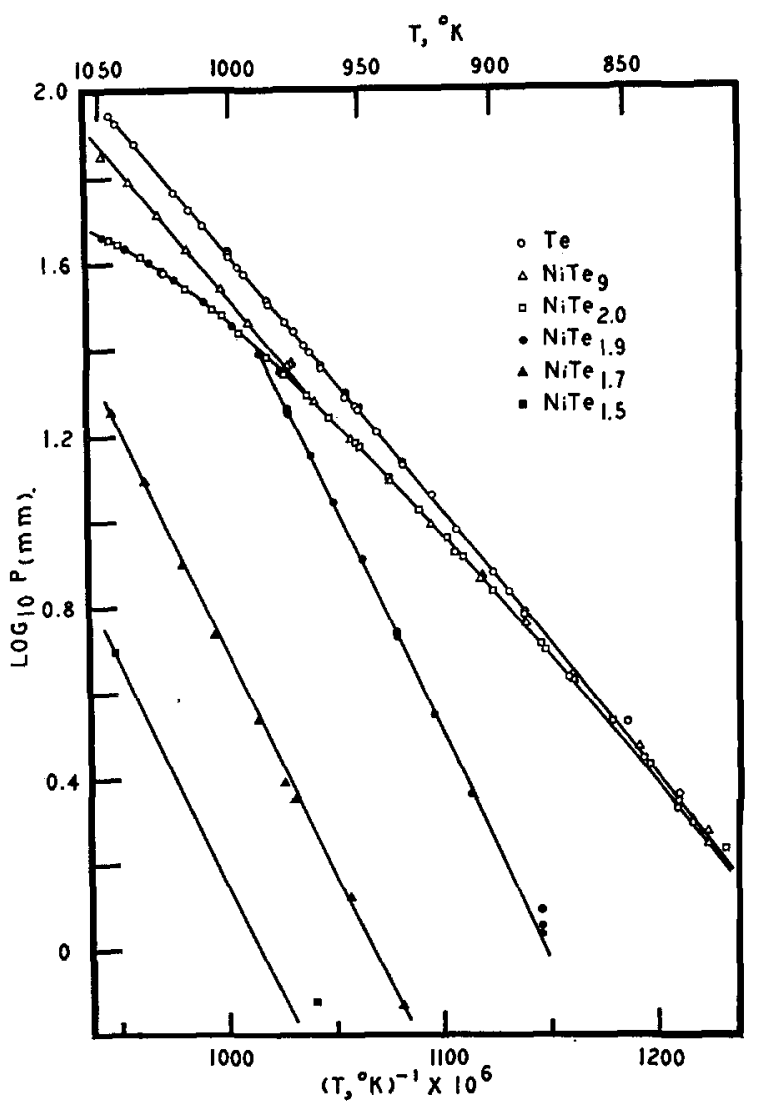

Fig. 2. Vapor pressure of tellurium and dissociation pressure of nickel tellurides as a function of temperature. 
The first point on $\mathrm{NiTe}_{1.5}$ is retained although it is known to be high because only one other point was obtained before the experiment was accidentally terminated, and that point has a probable error of about $0.3 \mathrm{~mm}$. All other points have a probable error of $0.1 \mathrm{~mm}$.

\section{Eutectic Measurement}

A sample of pure tellurium was saturated with nickel ditelluride by boiling vigorously in a silica vessel in vacuum at a temperature 250 degrees above the melting point, the necessary high temperature being obtained by restricting the egress of the tellurium vapor. The excess nickel ditelluride could be presumed to remain

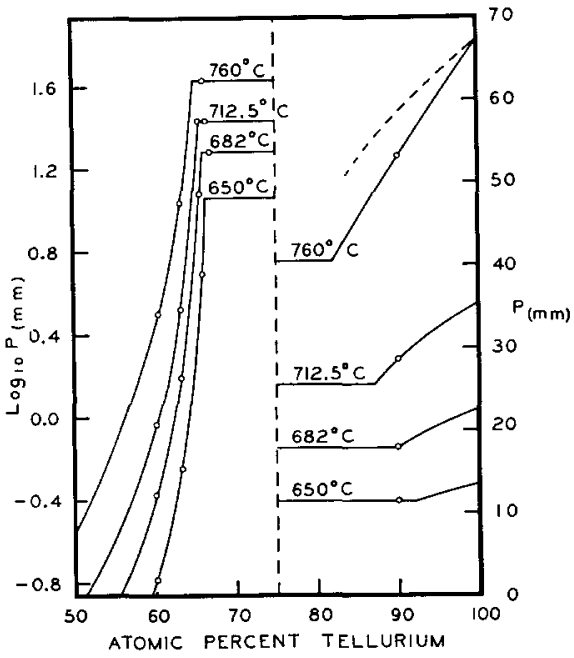

FIG. 3. Dissociation pressure of nickel tellurides as a function of composition.

in the bottom of the tube because of its higher density. ${ }^{4}$ The tube was then sealed, and the melting point determined as previously described ${ }^{5}$ for tellurium. The thermocouple was recalibrated immediately beforehand by redetermining the melting point of tellurium. The observed freezing point of the nickel-saturated tellurium solution was $1.0^{\circ}$ below that of pure tellurium. After cooling, the tube was broken and a sample of the metal removed from the central portion, and analyzed. It contained 0.3 atomic percent nickel.

\section{DISCUSSION}

The cryoscopic constant for tellurium has been measured $^{6}$ for several different metals and ranges from 510 to $535^{\circ}$ per mole solute per $100 \mathrm{~g}$ tellurium. Hence a freezing point lowering of $1.0^{\circ}$ corresponds to atomic fractions of $0.9975 \mathrm{Te}$ and $0.0025 \mathrm{Ni}$ as the eutectic composition. It seems improbable that the relative

${ }^{4}$ W. Klemm and N. Fratini, Z. anorg. u. allgem. Chem. 251, 222 (1943).

${ }_{5}$ R. E. Machol and E. F. Westrum, Jr., J. Phys. Chem. 62, 361 (1958).

${ }^{6}$ H. Pélabon, Ann. chim. et phys. (8) 17, 526 (1909).

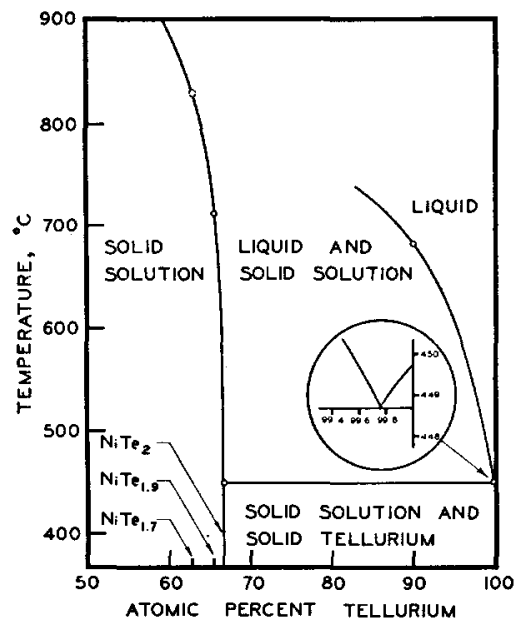

Fig. 4. Phase diagram of the nickel tellurium system.

temperature measurement was in error by more than $0.1^{\circ}$ or that the observed melting-point lowering was due to impurities other than nickel. However, it is possible that the solution was not saturated, in which case the true eutectic temperature may be slightly lower, and the true eutectic composition slightly richer in nickel.

The pressure data are shown in Fig. 2 as a function of temperature, with composition as a parameter, and the smooth curves are cross plotted in Fig. 3 to show pressure as a function of composition, with temperature as a parameter. The data in these figures are best interpreted in terms of the derived phase diagram (Fig.4). $\mathrm{NiTe}_{2}$ lies in the two-phase region at all temperatures measured, as do $\mathrm{NiTe}_{9}$ at temperatures below $682^{\circ}$ and $\mathrm{NiTe}_{1.9}$ at temperatures above $712.5^{\circ}$. The coincidence of the data for different compositions in the two-phase region supports the reliability of the data, particularly in the case of $\mathrm{NiTe}_{2}$ and $\mathrm{NiTe}_{9}$ with tellurium from different sources. Due to the rapidly increasing solubility of nickel in tellurium with in-

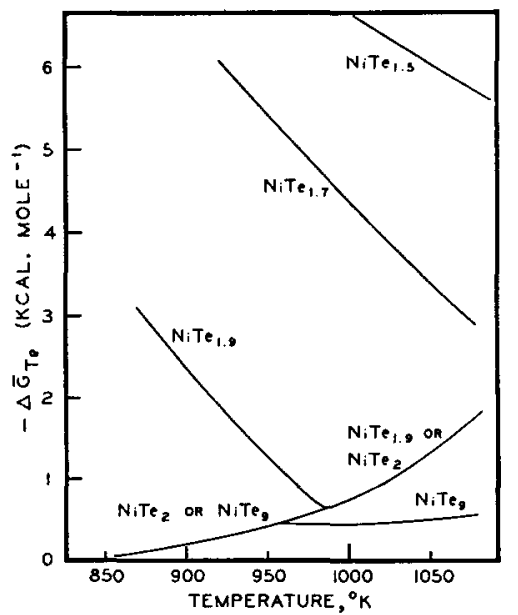

FIG. 5. Partial molal free energy of tellurium in nickel tellurides. 
TABLE II. Partial molal entropy and free energy of $\mathrm{Te}$ in $\mathrm{NiTe}_{x}$

\begin{tabular}{|c|c|c|c|}
\hline $\begin{array}{l}\text { Composi- } \\
\text { tion }\end{array}$ & $T,{ }^{\circ} \mathbf{K}$ & $\underset{\mathrm{mole}^{-1}}{\Delta \bar{G}_{\mathrm{T},}, \mathrm{cal}}$ & $\Delta \bar{S}_{\mathrm{Te}}, \underset{\mathrm{deg}^{-1}}{\mathrm{cal} \mathrm{mole}}$ \\
\hline $\mathrm{NiTe}_{1.5}$ & 1050.0 & 6005.0 & \\
\hline $\mathrm{NiTe}_{1.7}$ & $\begin{array}{l}1000.0 \\
1050.0\end{array}$ & $\begin{array}{l}4378.0 \\
3400.0\end{array}$ & $\begin{array}{l}-20.2 \\
-18.9\end{array}$ \\
\hline $\mathrm{NiTe}_{1.9}$ & $\begin{array}{r}900.0 \\
950.0 \\
985.6 \\
1000.0 \\
1050.0\end{array}$ & $\begin{array}{r}2375.0 \\
1259.0 \\
630.7 \\
748.3 \\
1318.0\end{array}$ & $\begin{array}{c}-24.1 \\
-20.7 \\
\\
8.50 \\
14.7\end{array}$ \\
\hline $\mathrm{NiTe}_{2,0}$ & $\begin{array}{r}900.0 \\
950.0 \\
955.1 \\
985.6 \\
1000.0 \\
1050.0\end{array}$ & $\begin{array}{r}200.9 \\
415.8 \\
437.7 \\
630.7 \\
748.3 \\
1318.0\end{array}$ & $\begin{array}{c}3.78 \\
4.94 \\
\\
\\
8.53 \\
14.7\end{array}$ \\
\hline $\mathrm{NiTe}_{9}$ & $\begin{array}{r}900.0 \\
950.0 \\
1000.0 \\
1050.0\end{array}$ & $\begin{array}{l}200.9 \\
414.2 \\
445.5 \\
492.3\end{array}$ & $\begin{array}{l}3.78 \\
4.94 \\
0.378 \\
1.85\end{array}$ \\
\hline
\end{tabular}

creasing temperature, $d^{2} P / d T^{2}$ becomes negative for $\mathrm{NiTe}_{2}$ at about $740^{\circ}$, and $d P / d T$ may be expected to become negative somewhat above $800^{\circ}$.

Although the curves of Figs. 3 and 4 are drawn through a small number of points, they may be considered reliable. In particular, only two points are available to determine the liquidus curve of Fig. 4, one from the singularity of the $P$ vs $T$ curve for $\mathrm{NiTe}_{9}$ at $682^{\circ}$ and one from the eutectic measurement. However, the curve joining these points must lie as shown, since any deviations would have been evident in the vapor pressure of the two-phase composition, which is of course equal to the vapor pressure of the liquidus composition at any temperature. The dotted line in Fig. 3 represents Raoult's law for $760^{\circ}$, assuming that the solute is $\mathrm{NiTe}_{2}$; the data deviate negatively from this line. (Alternatively, one might state that the solution follows Raoult's law with each nickel atom associated with somewhat more than two tellurium atoms.) Assuming that the deviations from Raoult's law are approximately the same at somewhat lower temperatures-and this assumption is consistent with the data, as shown in Fig. 3-the liquidus curve may be traced downward. Similarly, only two points are available on the solidus curve, one from the singularity of the $P$ vs $T$ curve for $\mathrm{NiTe}_{1.9}$ at $712.5^{\circ}$ and one from the low-temperature phase boundary, which lies between $\mathrm{NiTe}_{1.99}$ and $\mathrm{NiTe}_{2.00}$, as shown by $\mathrm{x}$-ray analysis. ${ }^{7}$ However, any irregularities in this solidus curve would certainly have been reflected in the pressure data, since the ratio of the pressure over $\mathrm{NiTe}_{1.9}$ to that over the two-phase composition is a measure of the horizontal distance in Fig. 4 between the solidus curve and the composition $\mathrm{NiTe}_{1.9}$.

The partial molal free energies (the free energy upon adding one mole of liquid tellurium to an infinite quantity of $\mathrm{NiTe}_{x}$ at the same temperature) are computed from

$$
\Delta \bar{G}_{\mathrm{Te}}=R T \ln \left(p / p_{0}\right)
$$

where $p$ is the equilibrium pressure over $\mathrm{NiTe}_{x}, p_{0}$ is the vapor pressure of tellurium ${ }^{8}$ at the same temperature, and $\Delta \bar{G}_{\mathrm{Te}}$ applies to one mole of tellurium as it exists in the gas phase -i.e., two gram-atoms. The partial molal free energies obtained from the smooth curves of Fig. 2 are plotted in Fig. 5. The slopes of these curves are the partial molal entropies, and are given in Table II. It will be noted that the partial molal entropy of tellurium in $\mathrm{NiTe}_{1.9}$ changes discontinuously, including a change of sign, at $985.7^{\circ} \mathrm{K}$. Above this temperature, tellurium added to $\mathrm{NiTe}_{\mathbf{s} .9}$ goes into the liquid portion of the two-phase mixture with a resulting increase of entropy, while below this temperature it goes into the homogeneous solid with a resulting decrease in entropy.

\section{ACKNOWLEDGMENTS}

We appreciate the assistance of Gunther Kessler who fabricated the silica apparatus. This work was supported in part by the Division of Research of the U. S. Atomic Energy Commission under contract AT(11-1)-70, Project No. 5.

${ }^{7} \mathrm{~J}$. Barstad and F. Grønvold, Acta Chem. Scand. (to be published).

${ }^{8}$ R. E. Machol and E. F. Westrum, Jr., J. Am. Chem. Soc. (to be published). 